\title{
Onchocerciasis in Ecuador: ocular findings in Onchocerca volvulus infected individuals
}

\author{
P J Cooper, R Proaño, C Beltran, M Anselmi, R H Guderian
}

\begin{abstract}
Little is known of the epidemiology and clinical picture of ocular onchocerciasis in South America. A survey of onchocercal eye disease was performed in the hyperendemic area of a rain forest focus of onchocerciasis in Esmeraldas Province in Ecuador. A total of 785 skin snip positive individuals from black and Chachi Amerindian communities were examined. The blindness rate attributable to onchocerciasis was $0.4 \%$, and $8.2 \%$ were visually impaired. Onchocercal ocular lesions were seen in a high proportion of the study group: $33.6 \%$ had punctate keratitis, microfilariae in the anterior chamber and cornea were seen in $28.9 \%$ and $33.5 \%$ respectively, iridocyclitis was seen in $1.5 \%$, optic atrophy in $5.1 \%$, and chorioretinopathy in $28 \cdot 0 \%$. Sclerosing keratitis was not seen. The prevalence of all ocular lesions increased with age. Punctate keratitis was strongly associated with microfilarial counts in the cornea and chorioretinopathy was correlated with infection intensities in the cornea and anterior chamber. Chachi Amerindians had higher anterior chamber microfilarial counts and a greater prevalence of punctate keratitis than blacks though blacks had a greater prevalence of iridocyclitis and optic nerve disease. The pattern of ocular disease resembled rain forest onchocerciasis in west Africa with few severe ocular lesions in the anterior segment and all blinding lesions attributable to posterior segment disease.
\end{abstract}

(Br f Ophthalmol 1995; 79: 157-162)

Onchocerciasis is a major blinding disease in the developing world. It is estimated that up to 18 million people are infected in Africa and Central and South America. ${ }^{1}$ Of these, approximately one million are blind or suffer severe visual loss. ${ }^{2}$

The clinical pattern of ocular onchocerciasis differs from one geographical region to another and sometimes between bioclimatic zones in the same region. ${ }^{3}$ For example, in west Africa, there are differences between rain forest and savannah forms of ocular onchocerciasis. The prevalence of iritis, chorioretinopathy, and optic atrophy is less in rain forest than in savannah areas. ${ }^{4-6}$ Blindness from onchocerciasis is between $2 \cdot 5^{7}$ and 5 times $^{6}$ more common in the savannah. Much of this excess is accounted for by the advanced sclerosing keratitis found in the savannah which is largely absent from the rain forest. ${ }^{7}$

In the Americas, foci of disease have been described in Mexico, Guatemala, Colombia, Venezuela, Brazil, and Ecuador. Earlier reports from Guatemala ${ }^{5}$ and Venezuela ${ }^{9}$ indicated ocular pathology attributable to onchocerciasis. The absence of comprehensive reports on the current status of ocular onchocerciasis in any of these foci has made it difficult to evaluate if blinding onchocerciasis remains a major problem in these regions.

The epidemiology of the rain forest focus of onchocerciasis in Esmeraldas Province of Ecuador has been extensively studied. ${ }^{10}$ Current evidence suggests that the prevalence and intensity of infection and its geographical boundaries are expanding. ${ }^{11} 12$ This is because of migration of infected individuals and the presence of a highly efficient vector, Simulium exiguum (Collins et al, unpublished observations).

There are no previous reports of the pattern of ocular onchocerciasis in Ecuador. This paper describes the detailed ocular findings of 785 Onchocerca volvulus infected individuals living in a hyperendemic area for onchocerciasis in Esmeraldas Province of Ecuador.

\section{Materials and methods}

\section{STUDY POPULATION}

The study was performed in the hyperendemic area of the rain forest focus of onchocerciasis in the Santiago river basin of Esmeraldas Province. ${ }^{10}$ The communities living in this area included both indigenous Amerindian (Chachi tribe) and black (of African descent) communities. The ethnographic features of these communities have been described elsewhere. ${ }^{13}$ Patients were selected from 35 villages. The single criterion for selection was a previously documented positive skin snip. Patients were brought by canoe to a central examination centre for ocular assessment. The following information was recorded for each patient: age, sex, race, house location, and previous antifilarial treatment.

\section{PARASITOLOGICAL EXAMINATION}

Skin biopsies were taken from both iliac crests with a Stolz corneoscleral punch. The biopsies were weighed and placed in micro well plates in saline. The number of emergent microfilariae were counted after 24 hours. The arithmetic mean of the two snips was calculated for each person. 
Table 1 Frequency distribution of study population by age, sex, and race

\begin{tabular}{|c|c|c|c|c|c|c|c|}
\hline & \multicolumn{6}{|c|}{ Age group (years) } & \multirow[b]{2}{*}{ Total } \\
\hline & $0-9$ & $10-19$ & $20-29$ & $30-39$ & $40-49$ & $50+$ & \\
\hline \multicolumn{8}{|l|}{ Race } \\
\hline $\begin{array}{l}\text { Black } \\
\text { Chachi }\end{array}$ & $\begin{array}{l}37(12.9 \%) \\
50(10.0 \%)\end{array}$ & $\begin{array}{r}82(28 \cdot 6 \%) \\
145(29 \cdot 1 \%)\end{array}$ & $\begin{array}{r}44(15 \cdot 3 \%) \\
131(26 \cdot 3 \%)\end{array}$ & $\begin{array}{l}36(12 \cdot 5 \%) \\
67(13 \cdot 5 \%)\end{array}$ & $\begin{array}{l}41(14 \cdot 3 \%) \\
52(10 \cdot 4 \%)\end{array}$ & $\begin{array}{l}47(16 \cdot 4 \%) \\
53(10 \cdot 6 \%)\end{array}$ & $\begin{array}{l}287(100 \%) \\
498(100 \%)\end{array}$ \\
\hline \multicolumn{8}{|l|}{ Sex } \\
\hline $\begin{array}{l}\text { Male } \\
\text { Female }\end{array}$ & $\begin{array}{l}36(8 \cdot 3 \%) \\
51(14 \cdot 5 \%)\end{array}$ & $\begin{array}{r}150(34.6 \%) \\
77(21.9 \%)\end{array}$ & $\begin{array}{r}84(19.4 \%) \\
91(25.9 \%)\end{array}$ & $60(13 \cdot 8 \%)$ & $\begin{array}{l}43(9 \cdot 9 \%) \\
50(14 \cdot 3 \%)\end{array}$ & $\begin{array}{r}61(14 \cdot 1 \%) \\
39(11 \cdot 1 \%)\end{array}$ & $434(100 \%)$ \\
\hline Total & $87(11 \cdot 1 \%)$ & $227(28.9 \%)$ & $175(22 \cdot 3 \%)$ & $103(13 \cdot 1 \%)$ & $93(11.9 \%)$ & $100(12 \cdot 7 \%)$ & $785(100 \%)$ \\
\hline
\end{tabular}

OPHTHALMIC EXAMINATION

Uncorrected visual acuity was tested by illiterate $\mathrm{E}$ or literate Snellen charts at 6 metres in broad daylight. If either acuity was $<6 / 12$, it was assessed with a pinhole. The following definitions for visual acuity were used: normal acuity as $6 / 18$ or better, visual impairment as an acuity of between $6 / 21$ and $3 / 60$, and blindness as less than 3/60. Binocular visual impairment represents visual acuity in the better eye. Slit-lamp examination was conducted after head down positioning of patients for $10 \mathrm{~min}$ utes using a Topcon slit-lamp. The numbers of microfilariae in the anterior chamber were counted. An arithmetic mean of counts from both eyes was calculated for each person. The following were also noted: the presence of live and dead microfilariae and punctate opacities in the cornea, sclerosing keratitis, and cataract. Any other abnormality of the anterior chamber structures was recorded. Intraocular pressure measurements were performed on both eyes using a Goldmann applanation tonometer (Haag-Streit). Glaucoma was defined as an intraocular pressure greater than $25 \mathrm{~mm} \mathrm{Hg}$ in the presence of optic disc cupping or an intraocular pressure greater than $40 \mathrm{~mm} \mathrm{Hg}$ in the absence of disc cupping. After pupil dilatation with $1 \%$ tropicamide and $10 \%$ adrenaline, the ocular fundus was examined with a Keeler indirect ophthalmoscope. The optic disc was examined for the presence of atrophy, papillitis, increased pigmentation, and sheathing of the central retinal vessels. Abnormalities of the retina and choroid were noted. Particular attention was paid to the presence of mottling or confluent atrophy of the retinal pigment epithelium (RPE) and chorioretinal scarring with pigment clumping, choriocapillary atrophy, or both.

Ocular examinations were performed by two experienced ophthalmologists. No systematic test of interobserver variation was performed.

Table 2 Geometric mean microfilarial intensities in the skin (MfS), anterior chamber (MfAC), and cornea $(M f C)$ by race and sex

\begin{tabular}{|c|c|c|c|}
\hline Race & $\begin{array}{l}M f S \\
(m f / m g)\end{array}$ & $\begin{array}{l}\text { MfAC } \\
\text { (mfleye) }\end{array}$ & $\begin{array}{l}M f C \\
\text { (mfleye) }\end{array}$ \\
\hline \multicolumn{4}{|l|}{ Black } \\
\hline Male & $22 \cdot 7$ & 0.4 & 0.4 \\
\hline Female & $21 \cdot 1$ & $0 \cdot 2$ & $0 \cdot 1$ \\
\hline Total & $22 \cdot 0$ & $0 \cdot \overline{3}$ & 0.3 \\
\hline \multicolumn{4}{|l|}{ Chachi } \\
\hline Male & $32 \cdot 0$ & $1 \cdot 0$ & 0.6 \\
\hline Female & $23 \cdot 5$ & 0.7 & 0.5 \\
\hline Total & $27 \cdot 6$ & 0.8 & 0.5 \\
\hline \multicolumn{4}{|l|}{ Sex } \\
\hline Male & $27 \cdot 8$ & 0.7 & 0.5 \\
\hline Female & 22.7 & 0.5 & 0.4 \\
\hline Total & $25 \cdot 4$ & 0.6 & 0.4 \\
\hline
\end{tabular}

STATISTICAL ANALYSIS

Infection intensities of microfilariae in the skin and anterior segment are expressed as the geometric mean number of microfilariae per individual. Infection intensities are expressed as microfilariae per $\mathrm{mg}$ of skin. Comparison of proportions were analysed using $\chi^{2}$ and of means using Student's $t$ test. Spearman's rank correlation coefficient was used to calculate the correlation between two variables. Statistically significant findings by any of these three methods $(p<0.05)$ were further analysed using multiple regression procedures to control for potential confounding factors. The regression methods used were multiple logistic regression for binary dependent variables and multiple linear regression for continuous dependent variables. The $p$ values given in the text are those obtained by the non-regression methods and the results of multiple regression procedures are only given where they do not confirm the findings of these analyses (at $p>0.05$ ). Adjustment for age, sex, and race was performed by direct standardisation using the total population of the hyperendemic area as standard.

\section{Results}

\section{STUDY POPULATION}

A total of 785 persons aged 5 years or more (range 5-80, median 25) underwent parasitological and ophthalmic examination. The age, sex, and race distribution of this study sample is shown in Table 1. There were no previous histories of treatment with antifilarial drugs in the study population.

\section{SKIN INFECTION INTENSITY}

The overall intensity of infection by skin snip

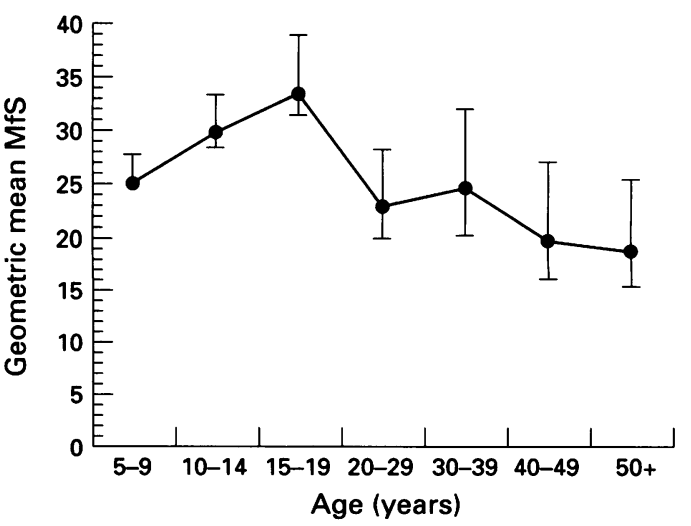

Figure 1 Geometric mean microfilarial intensity in the skin (MfS) by age. Means $+95 \%$ confidence intervals are shown. 
Table 3 Causes of blindness and visual impairment

\begin{tabular}{|c|c|c|c|c|}
\hline \multirow[b]{2}{*}{ Cause } & \multicolumn{2}{|c|}{ Visual impairment } & \multicolumn{2}{|l|}{ Blind } \\
\hline & Uniocular & Binocular & Uniocular & Binocular \\
\hline Onchocerciasis & $22(2 \cdot 8 \%)$ & $31(3.9 \%)$ & $8(1 \cdot 0 \%)$ & $3(0 \cdot 4 \%)$ \\
\hline Cataract & $0(0.0 \%)$ & $4(0.5 \%)$ & $0(0.0 \%)$ & $1(0 \cdot 1 \%)$ \\
\hline Glaucoma & $1(0 \cdot 1 \%)$ & $0(0.0 \%)$ & $0(0.0 \%)$ & $0(0.0 \%)$ \\
\hline Toxoplasmosis & $1(0 \cdot 1 \%)$ & $1(0 \cdot 1 \%)$ & $0(0.0 \%)$ & $0(0.0 \%)$ \\
\hline Refractive error & $0(0.0 \%)$ & $7(0.9 \%)$ & $0(0.0 \%)$ & $0(0.0 \%)$ \\
\hline Trauma & $0(0.0 \%)$ & $0(0.0 \%)$ & $2(0 \cdot 3 \%)$ & $0(0.0 \%)$ \\
\hline Other* & $1(0 \cdot 1 \%)$ & $2(0.3 \%)$ & $0(0.0 \%)$ & $1(0 \cdot 1 \%)$ \\
\hline Total & $25(3 \cdot 2 \%)$ & $45(5 \cdot 7 \%)$ & $10(1.3 \%)$ & $5(0.6 \%)$ \\
\hline
\end{tabular}

*Other findings include phthisis bulbi and aphakia.

examination was 25.4 microfilaria $(\mathrm{mf}) / \mathrm{mg}$. Geometric mean infection intensities (MfS) were highest in Chachi males $(32.0 \mathrm{mf} / \mathrm{mg}$ ) (Table 2). The Chachi $(27.6 \mathrm{mf} / \mathrm{mg})$ had higher counts than blacks $(22.0 \mathrm{mf} / \mathrm{mg})$ $(\mathrm{p}<0.01)$ and males $(27.8 \mathrm{mf} / \mathrm{mg})$ higher counts than females $(22.7 \mathrm{mf} / \mathrm{mg})(p<0.01)$. Microfilarial counts peaked between 15 and 19 years of age (33.3 $\mathrm{mf} / \mathrm{mg}$ ) (Fig 1) and declined gradually thereafter. This pattern was true for all race and sex groups (data not shown).

VISUAL IMPAIRMENT AND BLINDNESS

A total of $85(10.8 \%)$ individuals had uniocular or binocular impaired vision or blindness. Sixty four $(8 \cdot 2 \%)$ had onchocerciasis induced visual loss (Table 3). This accounts for $75.3 \%$ of people with visual loss. Five people $(0.6 \%)$ were bilaterally blind of whom three $(0.4 \%)$ were blind as a result of onchocerciasis. The distribution of visual loss according to race and sex is illustrated in Table 4. Most affected were black race and male sex. All onchocerciasis induced visual impairment or blindness was due to posterior segment disease.

ANTERIOR SEGMENT DISEASE

Punctate keratitis. Punctate corneal opacities were seen in $264(33.6 \%)$ people (Table 5).

Table 4 Visual impairment and blindness due to onchocerciasis according to race and sex

\begin{tabular}{|c|c|c|c|c|c|}
\hline & \multicolumn{2}{|c|}{ Visual impairment } & \multicolumn{2}{|l|}{ Blind } & \multirow[b]{2}{*}{ Total } \\
\hline & Uniocular & Binocular & Uniocular & Binocular & \\
\hline \multicolumn{6}{|l|}{ Race } \\
\hline Black & $10(3.5 \%)$ & $12(4 \cdot 2 \%)$ & $4(1 \cdot 4 \%)$ & $1(0 \cdot 3 \%)$ & $27(9 \cdot 4 \%)$ \\
\hline Chachi & $12(2 \cdot 4 \%)$ & $19(3.8 \%)$ & $4(0.8 \%)$ & $2(0.4 \%)$ & $37(7 \cdot 4 \%)$ \\
\hline \multicolumn{6}{|l|}{ Sex } \\
\hline Male & $14(3 \cdot 2 \%)$ & $19(4 \cdot 4 \%)$ & $7(1 \cdot 6 \%)$ & $2(0.5 \%)$ & $42(9 \cdot 7 \%)$ \\
\hline Female & $8(2 \cdot 3 \%)$ & $12(3.4 \%)$ & $1(0.3 \%)$ & $1(0.3 \%)$ & $22(6.3 \%)$ \\
\hline Total & $22(2.8 \%)$ & $31(3.9 \%)$ & $8(1.0 \%)$ & $3(0.4 \%)$ & $64(8 \cdot 2 \%)$ \\
\hline
\end{tabular}

Punctate keratitis was seen with equal frequency in both sexes. These lesions were seen more often in the Chachi $(36.8 \%$ versus $28.2 \%, \mathrm{p}<0.05$ ). Black females had a much lower prevalence of these lesions $(16 \cdot 1 \%)$ than the other sex and race groups. The prevalence of punctate keratitis increased with age (Fig 2). Fifty per cent of those aged 50 years or more had this lesion.

Microfilariae in the anterior chamber (MfAC). MfAC were seen in 227 (28.9\%) people. They were more prevalent in the Chachi than blacks (Table $5 ; 35.1 \%$ versus $18.1 \%, \mathrm{p}<0.001$ ). The geometric mean microfilarial counts in the anterior chamber were higher in the Chachi than blacks (Table $2 ; 0.8 \mathrm{mf} /$ eye/person versus $0.3 \mathrm{mf} / \mathrm{eye}, \mathrm{p}<0.001)$. There were no significant sex differences. Twenty four individuals (3.1\%) had counts of 20 microfilariae or more (range 0-91) in the anterior chamber. Of these 21 were Chachi and three were blacks. MfAC intensities were greatest in the 30 to 39 year age group (1.4 mf/eye/person) (Fig 3).

Microfilariae in the cornea (MfC). MfC were present in $263(33.5 \%)$ individuals (Table 5). The prevalence of $\mathrm{MfC}$ was higher in the Chachi $(40.6 \%$ versus $21 \cdot 3 \%, p<0.001)$. A greater number of microfilariae were seen in the corneas of the Chachi $(0.5 \mathrm{mf} /$ eye/person versus $0.3 \mathrm{mf} /$ eye, $\mathrm{p}<0.001$ ), but this did not remain significant after multiple regression analysis. MfC counts peaked in the 20-29 year age group $(0.7 \mathrm{mf} /$ eye/person) and then declined gradually (Fig 4).

Sclerosing keratitis. No definite cases of sclerosing keratitis were seen in the study group. Mild temporal, nasal, or semilunar corneal infiltration was seen in $17(2.2 \%)$ individuals but these were attributed to age related effects.

Iridocyclitis. A total of $12(1.5 \%)$ had evidence of past iridial inflammation with development of pupillary distortion, pigment loss, and anterior or posterior synechiae (Table 5). This was largely seen in blacks (3.1\% versus $0.6 \%, p<0.01)$. The prevalence of this lesion increased with age affecting $7 \cdot 0 \%$ of those aged 50 years or more (Fig 2).

\section{POSTERIOR SEGMENT DISEASE}

Chorioretinopathy. Active inflammation of the choroid and retina was not seen. Chorioretinopathy took the form of either atrophy of the retinal pigment epithelium (RPE) or chorioretinal scarring. This was seen in 220

Table 5 Onchocercal ocular lesions according to race and sex

\begin{tabular}{|c|c|c|c|c|c|c|}
\hline Race & $P K$ & $M f A C$ & $M f C$ & Irid & $O A$ & Chor \\
\hline \multicolumn{7}{|l|}{ Black } \\
\hline $\begin{array}{l}\text { Male } \\
\text { Female } \\
\text { Total }\end{array}$ & $\begin{array}{l}63(36 \cdot 0 \%) \\
18(16 \cdot 1 \%) \\
81(28 \cdot 2 \%)\end{array}$ & $\begin{array}{l}38(21 \cdot 7 \%) \\
14(12 \cdot 5 \%) \\
52(18 \cdot 1 \%)\end{array}$ & $\begin{array}{l}49(28 \cdot 0 \%) \\
12(10 \cdot 7 \%) \\
61(21 \cdot 3 \%)\end{array}$ & $\begin{array}{l}5(2.9 \%) \\
4(3.6 \%) \\
9(3.1 \%)\end{array}$ & $\begin{array}{c}19(10.7 \%) \\
4(3.6 \%) \\
23(8.0 \%)\end{array}$ & $\begin{array}{l}47(26 \cdot 9 \%) \\
25(22 \cdot 3 \%) \\
72(25 \cdot 1 \%)\end{array}$ \\
\hline \multicolumn{7}{|l|}{ Chachi } \\
\hline $\begin{array}{l}\text { Male } \\
\text { Female } \\
\text { Total }\end{array}$ & $\begin{array}{r}93(35 \cdot 9 \%) \\
90(37 \cdot 7 \%) \\
183(36 \cdot 8 \%)\end{array}$ & $\begin{array}{r}106(40.9 \%) \\
69(28.9 \%) \\
175(35.1 \%)\end{array}$ & $\begin{array}{r}109(42 \cdot 1 \%) \\
93(38.9 \%) \\
202(40.6 \%)\end{array}$ & $\begin{array}{l}2(0.8 \%) \\
1(0.4 \%) \\
3(0.6 \%)\end{array}$ & $\begin{array}{r}10(3.9 \%) \\
7(2.9 \%) \\
17(3.4 \%)\end{array}$ & $\begin{array}{r}74(28 \cdot 6 \%) \\
74(31 \cdot 0 \%) \\
148(29 \cdot 7 \%)\end{array}$ \\
\hline \multicolumn{7}{|l|}{ Sex } \\
\hline $\begin{array}{l}\text { Male } \\
\text { Female } \\
\text { Total } \\
\text { Adjusted total }\end{array}$ & $\begin{array}{c}156(36 \cdot 4 \%) \\
108(30 \cdot 8 \%) \\
264(33 \cdot 6 \%) \\
30 \cdot 7 \%\end{array}$ & $\begin{array}{r}144(33 \cdot 2 \%) \\
83(23.7 \%) \\
227(28.9 \%) \\
26.0 \%\end{array}$ & $\begin{array}{c}158(36 \cdot 4 \%) \\
105(29 \cdot 9 \%) \\
263(33.5 \%) \\
28 \cdot 2 \%\end{array}$ & $\begin{array}{l}7(1.6 \%) \\
5(1.4 \%) \\
12(1.5 \%) \\
1.2 \%\end{array}$ & $\begin{array}{c}29(6 \cdot 7 \%) \\
11(3 \cdot 1 \%) \\
40(5 \cdot 1 \%) \\
4.0 \%\end{array}$ & $\begin{array}{r}121(27 \cdot 9 \%) \\
99(28 \cdot 2 \%) \\
220(28 \cdot 0 \%) \\
22 \cdot 4 \%\end{array}$ \\
\hline
\end{tabular}

$\mathrm{PK}=$ punctate keratitis; $\mathrm{MfAC}=$ microfilariae in the anterior chamber; $\mathrm{MfC}=$ microfilariae in the cornea; Irid=iridocyclitis; $\mathrm{OA}=$ optic atrophy; Chor=chorioretinopathy. Adjusted total=ocular lesions standardised by age, sex, and race. 


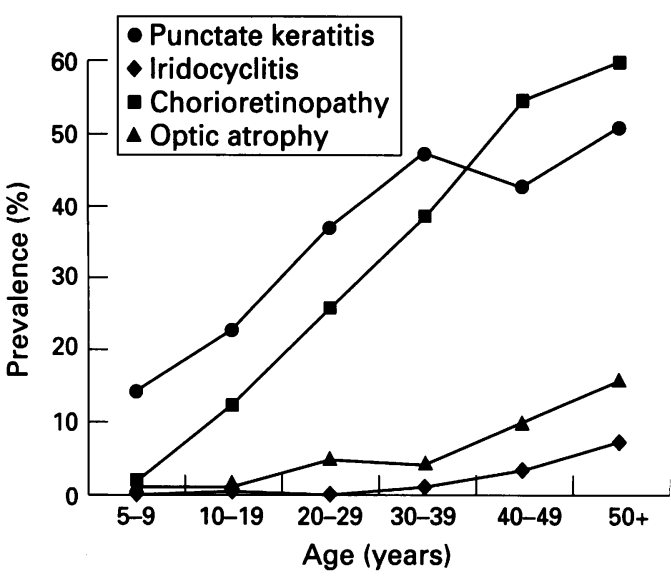

Figure 2 Prevalence of ocular lesions by age.

(28.0\%) individuals (Table 5). There were no significant race or sex differences. The prevalence of chorioretinopathy increased linearly with age affecting $59.0 \%$ of those aged over 50 years (Fig 2). RPE atrophy was seen as either greyish mottling or confluent atrophy. RPE atrophy was seen in $87(11 \cdot 1 \%)$ study participants. RPE atrophy was seen most frequently temporal to the fovea ( $79 \cdot 3 \%$ of cases) and was bilateral in $49.4 \%$ of affected individuals. Chorioretinal scarring was seen in 133 $(16.9 \%)$ people. The spatial distribution of these lesions in the retina was similar to that of RPE atrophy with $66.9 \%$ found in the temporal quadrant. Chorioretinal scarring was bilateral in $51.9 \%$ of cases.

Optic nerve disease. Non-glaucomatous optic atrophy was noted in $40(5 \cdot 1 \%)$ people (Table 5) and was frequently associated with increased peripapillary pigmentation and central retinal vascular sheathing. This lesion was predominantly seen in blacks $(8.0 \%$ versus $3.4 \%, \mathrm{p}<0.01)$ and males $(6.7 \%$ versus $3.1 \%$, $\mathrm{p}<0.05)$. There were four cases $(0.5 \%)$ of papillitis. The prevalence of optic atrophy increased with age, affecting $15.0 \%$ of those in the oldest age group (Fig 2). Of the 40 patients with optic atrophy, $36(90.0 \%)$ had evidence of other onchocercal ocular lesions, which is significantly greater than expected by chance $(\mathrm{p}<0.001)$. In addition, $29(72.5 \%)$ had chorioretinopathy (22 with chorioretinal scar-

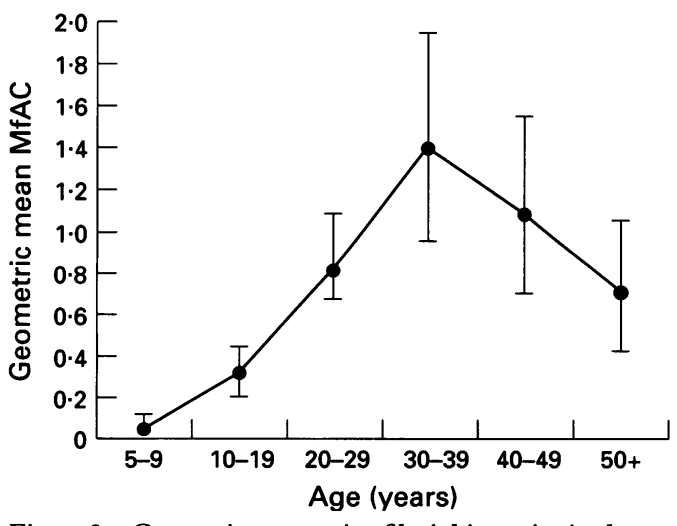

Figure 3 Geometric mean microfilarial intensity in the anterior chamber (MfAC) by age. Means +95\% confidence intervals are shown.

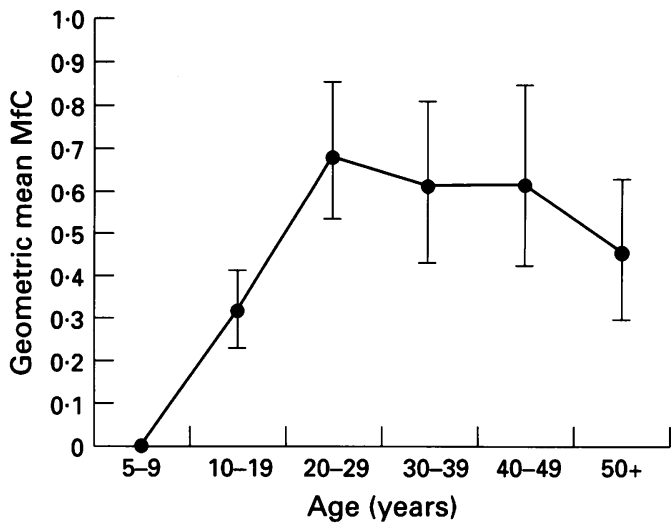

Figure 4 Geometric mean microfilarial intensity in the cornea (MfC) by age. Means $+95 \%$ confidence intervals are shown.

ring and seven with RPE atrophy). Glaucoma was seen in three $(0.4 \%)$ individuals.

Relation between ocular findings and microfilarial infection intensities. Geometric mean infection intensities in the skin and anterior chamber were strongly correlated (Table $6 ; \mathrm{p}<0.001$ ). Though MfS did not correlate with MfC, there was a strong correlation between MfAC and MfC $(\mathrm{p}<0.001)$. Punctate keratitis correlated significantly with $\mathrm{MfC}(\mathrm{p}<0.001)$, while chorioretinopathy correlated with both indices of ocular microfilarial intensity $(p<0.001)$. No associations between optic nerve disease and iridocyclitis and skin or eye microfilarial intensities were seen. The presence of chorioretinopathy and optic nerve disease were associated $(\mathrm{p}<0 \cdot 01)$.

\section{Discussion}

Visual impairment or blindness attributable to onchocerciasis was seen in $8 \cdot 2 \%$ of those examined and $0.4 \%$ were blind. Onchocerciasis accounted for $75 \cdot 3 \%$ of all visual loss in this study group. Equivalent estimates of blindness rates in other American foci are $0.5 \%$ (all causes) in Guatemala, $0.04 \%$ (all causes) in Mexico, and $0.14 \%$ in Venezuela. ${ }^{14}$ No onchocercal blinding lesions have been reported from Brazil and Colombia. ${ }^{14}$ These reports do suggest significant differences in blindness rates between the American foci. The blindness rate found in this study is likely to be a considerable underestimate of potential ocular morbidity for two reasons. Firstly, the mortality of blind people in this focus is extremely high and the life expectancy once blind is very short (unpublished observations). Blind people are not cared for by their communities and as the houses are scattered sparsely along the rivers, which is the only means of transport, the blind must, in order to survive, be able to navigate the rivers and cultivate subsistence crops unaided. High mortality of blind people with onchocerciasis have also been reported from west Africa where these may be three to four times greater than of people of the same age who can see. ${ }^{15}$ Secondly, there is evidence to suggest, even within the hyperendemic area, that the infection has appeared relatively recently. This is partly explained by 
Table 6 Univariate and multivariate analysis of the correlation between ocular findings and skin and eye microfilarial intensities

\begin{tabular}{|c|c|c|c|c|c|c|}
\hline & $M f S$ & $M f A C$ & $M f C$ & $P K$ & Irid & Chor \\
\hline MfAC & $(p<0.001)$ & & & & & \\
\hline $\mathrm{MfC}$ & - & $(\mathrm{p}<0.001)$ & & & & \\
\hline $\mathrm{PK}$ & - & $\mathrm{p}<0.01$ & $(\mathrm{p}<0.001)$ & & & \\
\hline Irid & - & - & - & - & & \\
\hline Chor & - & $(\mathrm{p}<0.001)$ & $(\mathrm{p}<0.001)$ & - & - & \\
\hline OA & - & - & - & - & - & $(p<0.01)$ \\
\hline
\end{tabular}

$\mathrm{MfS}=$ skin microfilarial intensity; $\mathrm{MfAC}=$ anterior chamber microfilarial intensity; $\mathrm{MfC}=$ corneal microfilarial intensity; Irid =iriodocyclitis; Chor=chorioretinopathy; $O A=0$ tic atrophy. $\mathrm{p}$ Values indicate results of Spearman's rank correlation coefficient and brackets signify a significant finding after multiple regression (at $\mathrm{p}<0.05)$.

the historically recent migrations of, first, the blacks and later the Chachi into the area. The Chachi are thought to have settled in the study area in the 1940 s. ${ }^{16}$ As blinding ocular lesions evolve slowly, the true burden of ocular disease has not yet had time to fully express itself.

A high proportion of the study population had evidence of ocular onchocerciasis (Table 5). The presence of microfilariae in the anterior chamber is often taken as an index of ocular disease in onchocerciasis: $33.5 \%$ of the study group had this finding. Of these, 24 $(3.1 \%)$ had 20 or more microfilariae in the anterior chamber. Twenty or more microfilariae in the anterior chamber is regarded as a risk factor for blinding onchocerciasis. ${ }^{3}$ Iridocyclitis was seen in only a few individuals $(1 \cdot 3 \%)$. This may be because only advanced iridocyclitis was included in the analysis (for example, the presence of pupillary distortion or anterior or posterior synechiae) resulting in an artificially low figure. Optic atrophy was seen in $5.1 \%$ of those examined and chorioretinopathy in $28.0 \%$. This pattern of ocular disease is similar to that seen in rain forest foci of west Africa where most cases of blindness are caused by chorioretinopathy and few by anterior segment disease. ${ }^{17-19}$

The pattern of ocular disease found in Ecuador differs from that described from other American foci of onchocerciasis. Ocular disease in Guatemala is characterised by severe anterior segment disease, particularly sclerosing keratitis and iritis which account for most cases of blindness. ${ }^{8}$ The severity of anterior segment disease in Guatemala is at least as great as that seen in savannah foci in Mali and Upper Volta. ${ }^{5}$ Relatively few posterior segment changes are seen in Guatemala: Monjusiau and co-workers, ${ }^{5}$ in an examination of 694 infected inhabitants of a hyperendemic area, noted $3 \cdot 7 \%$ to have chorioretinal changes and $0.3 \%$ with optic atrophy. In another series of 164 inhabitants from a similar area of Guatemala, ${ }^{20}$ fundal lesions were described in $6 \cdot 7 \%$. A more recent report from the southern Venezuelan focus described only anterior segment disease, ${ }^{14}$ though in 1959, Lagraulet ${ }^{9}$ reported characteristic fundal lesions in $11.9 \%$ of 277 infected individuals from the northern focus. Only anterior segment disease is reported from Brazil. ${ }^{14}$ Thus, there seem to be considerable differences between these foci both in terms of disease severity and clinical features. Such differences may reflect factors such as different parasite strains, environmental, or host differences. Parasite strain differ- ences have been proposed to explain the differences between the severity and pattern of ocular disease between rain forest and savannah areas of west Africa ${ }^{21}$ as well as similar differences between rain forest foci in the Ivory Coast and Sierra Leone. ${ }^{22}$

The mean microfilarial loads in the anterior chamber of the eye and the skin were significantly correlated. This pattern is also seen in savannah $^{23}$ and rain forest ${ }^{22} 24$ areas of west Africa. These findings support the view that the level of ocular invasion is directly related to dermal microfilarial intensities. ${ }^{25}$

Punctate keratitis was strongly associated with microfilarial counts in the cornea. This is not surprising as these lesions are directly caused by invading microfilariae. The relation between chorioretinopathy and both indices of ocular microfilarial invasion is less clear, but suggests a similar pathogenesis. Similar findings have been reported by others. ${ }^{19} 23$ The absence of a relation between microfilarial intensities and the prevalence of iridocyclitis and optic nerve disease is not clear. Clear associations of this kind have been reported in the savannah $^{23}$ but not the rain forest ${ }^{181924}$ of west Africa. The relation with optic atrophy may be more indirect as most cases were associated with chorioretinopathy, particularly chorioretinal scarring, suggesting atrophy consecutive to retinal disease. In addition, unpublished observations over the past 10 years point to large increases in the prevalence of both posterior segment lesions which parallel the large increases in prevalence and intensity of infection already reported. ${ }^{10-12}$

A number of race and sex differences were seen in microfilarial indices and ocular lesions. MfS levels were significantly elevated in both the Chachi and males. Raised skin counts in males is a common finding ${ }^{26}$ and may reflect increased exposure or hormonal factors. ${ }^{27}$ Likewise, higher skin burdens in the Chachi may reflect greater exposure to blackflies. Punctate keratitis and MfAC levels were greater in the Chachi which may be explained by the greater skin infection intensities seen in this group. The reason for the increased frequency of iridocyclitis and optic atrophy in blacks is unclear. Alternative aetiologies of optic atrophy such as toxins and nutritional deficiencies were considered but the close relation with chorioretinopathy and all other ocular lesions combined as well as the epidemiological changes over the last decade (discussed above), make such alternative explanations unlikely. The increased prevalence of optic atrophy, as well as iridocyclitis, in blacks may more simply reflect a racial susceptibility to this type of pathology. Racial differences in the prevalence of ocular lesions in onchocerciasis have been investigated by others. In one study iridocyclitis was found to be more prevalent in Guatemalans and optic atrophy more prevalent in west Africans ${ }^{5}$ and in another more severe iridocyclitis was seen in Guatemalans than in east African onchocerciasis, though there were no differences in prevalence of fundal lesions. ${ }^{20}$ However, the comparison of geographically separated racial 
groups is a less satisfactory approach as a number of factors that may influence the prevalence of ocular lesions such as parasite strain and transmission rate are certain to differ. With the exception of optic nerve disease, there were no sexual differences in the prevalence of ocular lesions. This is often seen in rain forest foci of west Africa. ${ }^{26}$

Our results demonstrate significant rates of ocular morbidity in this rain forest focus of onchocerciasis. These findings represent ocular disease found in those infected living in the hyperendemic focus and thus reflect ocular disease at its severest in the Esmeraldas focus. Possible biases resulting in the self selection into the study of those with ocular lesions cannot be excluded as we do not have comparable data on those eligible but who were not recruited into the study. If such biases were present we would expect the dermal microfilarial counts, which correlate with several ocular lesions, to be higher than that found in the general population. In fact, the study group had lower counts (data not shown). Likewise, though there were differences in the age-sex-race composition between the study group and general population, standardisation for these factors resulted in only slightly reduced estimates for all ocular lesions (Table 5). Therefore, our results are likely to be a true reflection of the situation in the hyperendemic area where $87.6 \%$ of the population are infected. ${ }^{10}$

It is hoped that with the mass distribution of ivermectin, currently under way, that the development of new lesions and progression of old lesions may be arrested and that the continuing evolution of ocular onchocerciasis that the unique epidemiology of this focus suggests, may be halted.

We thank Tony Fulford for statistical advice and Allen Foste and Clare Gilbert for helpful comments on the manuscript. Th work was supported by Christoffel Blindenmission. PC was supported by a training award from the British Medical Research Council and a Sackler studentship. Keeler Ltd is thanked for the loan of an indirect ophthalmoscope and the British Council for the Prevention of Blindness for a grant to purchase it.

1 World Health Organisation Expert Committee on Onchocerciasis, third report. Technical Report Series 752 Geneva: WHO, 1987.

2 Thylefors B. Onchocerciasis. Community Eye Health 1989 3: 5-6.

3 World Health Organisation. The pathogenesis and treatment of ocular onchocerciasis: report of the eighth meeting of the scientific working group on filariasis. TDR/FIL SWG(8)/82.3.

4 Budden FH. Comparative study of ocular onchocerciasis in 'savanna and rain forest. Trans $R$ Soc Trop Med Hyg 1963; 57: 64-70.

5 Monjusiau AGM, Lagraulet J, d'Haussy R, Goeckel GW. Aspects ophthalmologiques de l'onchocercose au Guatemala et en Afrique occidentale. Bull Org Mond Sante 1965; 32: 339-55.
6 Prost A. Le polymorphisme des onchocercoses humaines ouest-africaines. Ann Parasitol 1980; 55: 239-45.

7 Anderson J, Fuglsang H, Hamilton PJS, Marshall TF de C. Studies on onchocerciasis in the United Cameroon Republic. 11. Comparison of onchocerciasis in rain fores and Sudan-savanna. Trans $R$ Soc Trop Med Hyg 1974; 68: 209-22.

8 Choyce DP. Onchocerciasis: ophthalmic aspects. Trans $R$ Soc Trop Med Hyg 1966; 60: 720-34.

9 Lagraulet. Lesions oculaires, biopsies cutanees et localisation des nodules, chez les onchocerquiens du Venezuela. Bull Soc Path Exot 1960; 53: 703-11.

10 Guderian RH, Beck BJ, Proano SR, Mackenzie CD. Onchocerciasis in Ecuador, 1980-1986: epidemiological evaluation of the disease in the Esmeraldas Province. Eur F Epidemiol 1989; 5: 294-302.

11 Guderian RH, Beck BJ, Proaño SR. Onchocerciasis in Ecuador: infection in children in the Santiago Basin focus, Province of Esmeraldas. Trans $R$ Soc Trop Med Hyg 1990 84: $109-12$.

12 Guderian RH, Shelley AJ. Onchocerciasis in Ecuador: the situation in 1989. Mem Inst Oswaldo Cruz 1992; 87: 405-15.

13 Guderian RH, Leon LA, Leon R, Corral F, Vasconez C, Johnston TS. Report on a focus of onchocerciasis of Esmeraldas province of Ecuador. Am $\mathcal{F}$ Trop Med Hyg 1982; 31: 270-4

14 Inter-American Conference on Onchocerciasis. National plans for the control of onchocerciasis in the Americas. Quito, 1992.

15 Prost A, Vaugelade J. La surmortailite des aveugles en zone de savane Ouest-Africaine. Bull WHO 1981; 59: 773-6.

16 Espin Diaz J. Informe del 'Diagnostico preliminar de la situacion actual de los recursos forestales en los bosques de cinco zonas de la provincia de Esmeraldas'. Fundacion Natura. Quito, 1992

17 Semba RD, Murphy RP, Newland HS, Awadzi K, Green BM, Taylor HR. Longitudinal study of lesions of the posterior segment in onchocerciasis. Ophthalmology 1990 97: $1334-41$.

18 Dadzie KY, Remme J, Baker RHA, Rolland A, Thylefors B Ocular onchocerciasis and intensity of infection in the community. III. West African rain forest foci of the vector Simulium sanctipauli. Trop Med Parasitol 1990; 41: 376-82.

19 Newland HS, White AT, Greene BM, Murphy RP, Taylor HR. Ocular manifestations of onchocerciasis in a rain forest HR. Ocular manifestations of onchocerciasis in a rain fore
area of West Africa. $B r ₹$ Ophthalmol 1991; 75: 163-9.

20 Woodruff AW, Choyce DP, Muci-Mendoza F, Hills $M$ Pettit LE. Onchocerciasis in Guatemala. A. Clinical and parasitological studies with comparison between the disease there and in East Africa. Trans $R$ Soc Trop Med Hyg 1966; 60: 707-19.

21 Duke BOL, Lewis DJ, Moore PJ. Onchocerca-Simulium complexes 1 - transmission of forest and Sudan-savanna strains of Onchocerca volvulus from Cameroon by Simulium damnosum from various West-African bioclimatic zones. Ann Trop Med Parasitol 1966; 60: 318-36.

22 Dadzie KY, De Sole G, Remme J. Ocular onchocerciasi and the intensity of infection in the community. 4. The degraded forest of Sierra Leone. Trop Med Parasitol 1992 43: 75-9.

23 Remme J, Dadzie KY, Rolland A, Thylefors B. Ocula onchocerciasis and intensity of infection in the com munity. 1. West African savanna. Trop Med Parasitol $1989 ; 40: 340-7$

24 Dadzie KY, Remme J, Rolland A, Thylefors B. Ocular onchocerciasis and intensity of infection in the community. 11. West African rainforest foci of the vector. Simulium yahense. Trop Med Parasitol 1989; 40: Simulium

25 Anderson J. Fuglsang H, Marshall TF de C. Studies on onchocerciasis in the United Cameroon Republic. III. A four-year follow-up of 6 rain-forest and 6 savanna villages. The incidence of ocular lesions. Trans $R$ Soc Trop Med Hyg 1976; 70: 362-73.

26 Brabin L. Factors affecting the differential susceptibility of males and females to onchocerciasis. Acta Leidensa 1990; 59: 413-26.

27 Anderson J, Fuglsang H, Hamilton PJS, Marshall TF de C. Studies on onchocerciasis in the United Cameroon Republic 1 . Comparison of populations with and without Onchocerca volvulus. Trans $R$ Soc Trop Med Hyg 1974; 68: $190-208$. 